\section{Reduced Benzo(a)pyrene and Phenolic Content of Smoke from Experimental Cigarettes}

THE properties of tobacco and non-tobaceo leaves can be modified by subjecting these leaves to a series of chemical extractions which strip the whole leaf, or shredded leaf, to almost pure cellulose. This extraction process removes unhealthy substances and improves the flavour and aroma of such leaves when they are used as a smoking product. The extracted leaf is reconstituted, preferably to its original weight, by adding back non-toxic chemical agents which enhance the burning qualities, flavour and aroma.

In recent years increasing statistical ovidence has associated cigarette smoking with increased death rates from lung cancer and other diseases, notably coronary heart disease, emphysema and chronic bronchitis ${ }^{1}$. Recently, an advisory committee to the Surgeon General of the United States claimed to have established a causal relationship between eigarette smoking and lung disease.

Nearly 500 different chemical compounds have been isolated from cigarette condensate, including numerous polycyclic, aromatic, and other organic and inorganic compounds. Many of these compounds are carcinogenic and toxic when assayed on animals.

Polycyclics generally initiate the carcinogenic process and several polycyclic hydrocarbons are complete carcinogens. Because only relatively small amounts of polycyclics are present in the unburned leaf, they must be formed during the burning process from materials inherent in the leaf ${ }^{2}$. Polycyclics may be formed on pyrolysis of cellulose, lignin, pectin, starch, sucrose, glucose, and fructose and of citric, malic, and oxalic acids. Pyrolysis of tobacco paraffins at temperatures higher than $600^{\circ} \mathrm{C}$ yields polycyclics ${ }^{3}$. Incomplete pyrolysis of sterols may also produce polycyclics. An efficient extraction process should remove sterols, paraffins, and other possible precursors of polycyclics. Recent evidence indicates that polonium-210 may also initiate the carcinogenic process 5 . Polonium-210 should also be removed with an adequately designed extraction process.

The polycyclic fractions from cigarette smoke condensate account for less than 10 per cent of the carcinogenic activity of cigarette tar. It is believed that co-carcinogenic compounds are responsible for more than 90 per cent of the carcinogenic activity in the smoke condensate ${ }^{6}$. Several phenols are known to be co-carcinogens ${ }^{7}$ : phonol, dimethylphenol, ethylphenol and ortho-, meta-, and paracresol are all present in cigarette smoke condensate ${ }^{8}$. Other types of substances as yet unidentified may also be promoting substances. Co-carcinogens have been demonstrated in the alkaline extracts of unburned tobacco'.

The burning process may release co-carcinogens by either dry distillation or by incomplete destruction of usually non-carcinogenic compounds. (Dry distillation is the volatilization of substances which arises because of high temperatures near the burning zone of an ignited eigarette.) These substances are transmitted unchanged to the mainstream smoke. A second way in which cocarcinogens may arise is through incomplete pyrolysis of materials inherent in the leaf. Rearrangements, oxidations, cracking, dehydrogenation and condensation reactions may convert usually non-carcinogenic compounds into carcinogens.

Sun-cured soybean leaves wore first shreddod with a model 00 Himhoff cutter at a standard cut of 30 cuts/in. The shredded leaves were placed in stainloss-steel wiremesh baskots, and these baskets were raised or lowered frequently out of larger stainless-steel drums containing the solvents. The proportions of dry leaf to solvent were kept constant. Twenty millilitres of extracting solvent were used per gram of initial unextracted shredded dry leaf. All the extractions were carried out for $50 \mathrm{~min}$ at $55^{\circ} \mathrm{C}$. The leaves were first rinsed twice with water under the aforementioned conditions. These two rinse
Table 1. Results of Phenol, Benzo(a)ptrene, and Tar analyses of

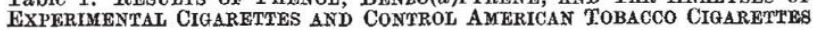

$\begin{array}{lccc}\text { Cigarette } & \text { Tar/cig. } & \text { Phenol/cig. } & \text { BP/cig. } \\ (\mathrm{mg}) & (\gamma) & 0.046 & 1.50 \\ \text { Non-tobacco } & 10 \cdot 6 & 0.27 & 6.15 \\ \text { Tobacco } & 38.6 & 0.27 & \end{array}$

solutions were discarded. Fresh water was heated to $55^{\circ} \mathrm{C}$ and added to the stainless-steel containers. Sodium chlorite was added until its concentration was 1 per cent. The $p H$ was adjusted to 4 with glacial acetic acid and the leaves were again lowered into the solution. After discarding the bleach solution, the leaves were rinsed twice with water to remove the bleach. Acetone was the final extracting solvent. The baskets were then raised and allowed to drain. The shredded leaves were removed from the baskets and air dried.

The shredded leaves were then flavoured with several ingredients to ensure the proper hydroscopic and burning qualities. In this experiment the compounds used were: 10 per cent invert sugar, 5 per cent glycerol, 2 per cent honey, 1.5 per cent St. John's bread (that is, ground meal from the ripe fruit of Ceratonica siliqua), 1 per cent cocoa and 3 per cent potassium nitrate (solected on the basis of their low benzoid content). The ingredients were sprayed on to the shredded leaves in a rotary drum. To ensure a good tobacco flavour, various non-carcinogenic fractions of tobacco extract could be added to the flavouring mixture ${ }^{10} .50 \mathrm{lb}$. completed leaves was adjusted to a humidity content of 13 per cent. Cigarettes of the thus prepared flavoured shredded leaves were made in an American Machine and Foundry cigarette maker.

$85-\mathrm{mm}$ cigarettes were smoked on a standard Ecusta smoking machine. Standard American cigarettes were used as controls. Smoking parameters were set at a $35 \mathrm{ml}$. puff of $2 \mathrm{sec}$ duration at $1 \mathrm{~min}$ intervals. The average butt length was $22 \mathrm{~mm}$. Tars were collected on a previously weighed Cambridge filter. After the tar had been eollected, the filter was weighed again. Phenols were determined by the method of Oakley et al. ${ }^{11}$. Benzo. (a) pyrene analyses were made by the method of Wynder ${ }^{12}$. Results of the phenol and benzo $(a)$ pyrene analyses are given in Table 1 .

The extraction process reduces the tar content per cigarette to only 27.4 per cent of a standard American cigaretto (Table 1). Phenols were also reduced to 17 per cent of the control. The reduction of benzo(a)pyrene suggests that it arises during the burning process through re-arrangement of complex polyphenols, steroids or other precursors inherent in the leaf. The extraction process also almost completely removes amino-acids, other nitrogen compounds and sulphur compounds. Toxic compounds, such as nitrogen dioxide, methyl nitrite, hydrogen cyanide and hydrogen sulphide are also probably considerably reduced in concentration in the mainstream smoke.

The great reduction of tar, phenols, benzo(a)pyrene and toxic substances indicates that it is possible to design a relatively safe cigarette.

Department of Biochemistry,

\section{R. J. SHAMberger*}

Sotton Medical Institute,

Montorey, California.

* Present address: Roswell Park Memorial Institute, Buffalo, New York.

${ }_{1}$ Smoking and Health: Report of the Advisory Committee to the Surgem General. Public Health Service Publication No. 1103 (U.S. Govermment Printers, Washington, D.C.).

2 Gilbert, J. A. S., and Lindsey, A. J., Brit. J. Cancer, 11, 398 (1957).

- Lam, J., Acta Pathol. Microbiol. Scand., 87, 421 (1955).

Kosak, A. I., Swinehart, J. S., Taber, D., and Van Duuren, B. L., Science, 125, 991 (1957).

${ }^{5}$ Radford, E. P., and Hunt, V. R., Science, 143, 247 (1964).

- Wynder, E. L., and Hoffman, D., Cancer, 14, 1306 (1961).

${ }^{7}$ Boutwell, R. K., and Bosch, D. K., Cancer Res., 19, 413 (1959).

${ }^{8}$ Hoffman, D., and Wynder, E. L., Beitr. Tabakforsch., 1, 101 (1961).

${ }^{9}$ Bock, F. G., Moore, G. F., and Crouch, S. K., Science, 145, 831 (1964).

${ }^{10}$ Bock, F. G., Shamberger, R. J., and Myers, H. K., Nature, 208, 584 (1965).

$"$ Oakley, E. T., William, J. O., and Weissbecker, L., Anal. Chem. Acte, 31, 272 (1964).

12 Hoffman, D., and Wynder, E. L., Anal. Chem., 32, 295 (1960). 